\title{
Pricing Liquidity Risk on the Tokyo Stock Exchange: Empirical Analysis Using Multiple Liquidity Measures
}

\author{
Xin Zhong \\ Osaka University \\ Hitoshi Takehara \\ Waseda University
}

This study investigates the effectiveness of the liquidity-adjusted capital asset pricing model proposed by Acharya and Pedersen (2005). Using Japanese data, we compute multiple liquidity measures and a principal-component-based liquidity proxy to examine whether liquidity risk is priced on the Tokyo Stock Exchange. We find that the size and value effect should be considered together when studying the pricing of liquidity risk. Through our analysis, we suggest using the principal-component-based liquidity proxy or using multiple methods to estimate Japanese stock liquidity. To some extent, liquidity risk is priced on the Tokyo Stock Exchange.

\section{INTRODUCTION}

The role of liquidity in asset pricing has grown rapidly over the past few years. A number of theories describe the effect of liquidity on the required returns of capital assets, and these theories predict that both the level of liquidity and the liquidity risk are priced. Many empirical studies have tested these theories and have verified that the effect of liquidity on asset prices is not only statistically significant but also economically important. Analyzing a liquidity-based asset pricing model can help to explain the crosssection of stock returns and, therefore, can aid in understanding the mechanism by which an increase in stock illiquidity results in a reduction in stock prices and an increase in expected stock returns. Thus, liquidity can play an important role in resolving asset pricing problems.

Liquidity, or the degree to which a security can be traded without affecting its price, is hard to estimate in the real world. Prior studies develop liquidity measures based on different aspects of liquidity. For example, Amihud (2002) proposes a liquidity measure estimated using asset returns and trading volumes to capture the daily price response associated with the trading volume. Pastor and Stambaugh (2003) propose the " $\gamma$ " measure, that is, an asset's sensitivity to innovations in aggregate liquidity, to estimate the asset's price impact. Datar (1998) uses the turnover ratio as a proxy for liquidity. Liu (2006) defines a standardized turnover-adjusted measure of zero daily trading volume, LMx, to capture liquidity dimensions, especially with respect to trading speed. Lesmond, Ogden, and Trzcinka (1999) propose a measure of marginal trading cost by estimating the incidence of zero returns. Roll (1984) proposes an estimator of effective spread based on the serial covariance of price changes. All of these measures have separate focuses. Specifically, Amihud (2002) and Pastor and Stambaugh (2003) measure the price 
impact, Datar (1998) considers the trading quantity, Liu (2006) emphasizes the trading speed, Lesmond, Ogden, and Trzcinka (1999) focus on the marginal trading cost, and Roll (1984) estimates the effective spread.

Given the limitations of a single liquidity measure, this study analyzes the pricing of liquidity risk using multiple liquidity measures. The analysis is based on the liquidity-adjusted capital asset pricing model (LCAPM) first proposed by Acharya and Pederson (2005). However, Acharya and Pederson (2005) only test the LCAPM using a single liquidity measure, that is, the ILLIQ measure proposed by Amihud (2002). Kim and Lee (2014) estimate the pricing of liquidity in the US stock market using multiple illiquidity measures. They prove that the systematic common component across different illiquidity measures can capture a significant liquidity premium, whereas a single illiquidity measure cannot, based on Korajczyk and Sadka's (2008) finding of the existence of a common liquidity component. However, Kim and Lee's (2014) sample data are only related to the US stock market, and no studies have investigated whether the LCAPM is appropriate for other security markets, such as the Japanese stock market, which is the second-largest financial market in the world. Moreover, no previous studies explicitly discuss which liquidity proxy most effectively reflects the Japanese stock market. Thus, the aim of this study is to test whether the LCAPM is feasible in the Japanese stock market and to select the most appropriate liquidity measure for that market.

This study first investigates the pricing of liquidity risk in the Japanese stock market by applying multiple illiquidity measures to the LCAPM and examining whether the empirical results vary according to the measure used. We find that the size and value effect should be considered together when studying the pricing of liquidity risk because they drastically increase the significance of the liquidity risk and improve the explanatory power of the model. Based on liquidity net risk, referred to as beta 5 in the LCAPM model, we find that liquidity risk is generally priced in the Japanese stock market. Thus, we further investigate the sources of this liquidity risk. However, the results are sensitive to the test assets (Brennan et al., 1998; Berk, 2000) and liquidity measures. Given the significance of the liquidity betas and the explanatory power of the model, we suggest using the measures of Amihud (2002), Datar (1998), and Lesmond, Ogden, and Trzcinka (1999) to estimate Japanese stock liquidity.

To further verify this conclusion and obtain a unified result, we apply the principal component analysis (PCA) framework to investigate whether the systematic common liquidity is related to individual security returns. We find that different components measure different aspects of liquidity. Specifically, the principal components that we use are high correlated with the liquidity measures proposed by Datar (1998), Lesmond, Ogden, and Trzcinka (1999), and Amihud (2002). These measures focus on the trading quantity, the trading cost, and the price impact, respectively. Thus, we infer that these three aspects are the most important liquidity dimensions in Japanese stock market.

We also run cross-sectional regressions using the PCA-based liquidity proxy. The results confirm that market capitalization and the book-to-market ratio should be incorporated in the model. Moreover, we find that the traditional trading cost and the liquidity-adjusted market risk have significant effects in all cases. In addition to the traditional illiquidity, the liquidity risks caused by the comovement between the security's price and the market liquidity and that between the security's liquidity and the market return are priced. Furthermore, the explanatory power of the regressions that use the PCA-based liquidity proxy is 1\% higher than the highest adjusted R-squared value for the regressions based on single illiquidity measures. The model therefore improves slightly when using principal components rather than a single illiquidity measure.

The contribution of this study is that it verifies the existence of the pricing of liquidity risk beyond the level of illiquidity and the traditional market risk in the Japanese stock market using both six single liquidity measures and a PCA-based liquidity proxy. Our findings suggest that using principal components to study the pricing of liquidity risk is superior to using a single illiquidity measure in terms of the R-squared value for cross-sectional returns and the p-values in the specification tests. However, we also recommend using the measures of Datar (1998), Lesmond, Ogden, and Trzcinka (1999), and Amihud (2002) to capture Japanese stock liquidity based on the results of Pearson correlation tests with the principal components and of cross-sectional regressions using those liquidity measures. Moreover, we 
also infer that the trading quantity, the trading cost, and the price impact are the most important aspects of liquidity in the Japanese stock market in view of the outstanding performance of those related liquidity measures.

The remainder of the paper is organized as follows. Section 2 briefly introduces the LCAPM of Acharya and Pederson (2005). The data screening and liquidity measures are described in Section 3. Section 4 explains the process of computing liquidity risk factors in the LCAPM. The empirical results of cross-sectional regressions are summarized in Section 5. Section 6 concludes.

\section{LIQUIDITY-ADJUSTED CAPITAL ASSET PRICING MODEL}

The capital asset pricing model (CAPM) provides a powerful and intuitive measure of the relationship between the expected return and systematic risk of an asset using the covariance between the asset's return and the market return. However, some empirical studies show that CAPM pricing is weak, probably because it involves numerous theoretical assumptions, such as a frictionless market and homogeneous expectations, and because implementing valid tests of the model is difficult (Fama and French, 2004).

Acharya and Pedersen (2005) consider a more realistic market with illiquidity costs and derive a liquidity-adjusted version of the CAPM by substituting the stock trading-cost-free return in the CAPM with the stock trading-cost-adjusted return. Compared with the standard CAPM, the LCAPM presents a unified theoretical framework that helps explain the effects of different liquidity risks on asset prices, and it fares better than the standard CAPM does in terms of $R^{2}$ values for cross-sectional returns and $p$-values in specification tests. The LCAPM is presented as

$$
E_{t}\left(R_{i, t+1}-C_{i, t+1}\right)=R_{f, t}+\lambda_{t} \frac{\operatorname{Cov}_{t}\left(R_{i, t+1}-C_{i, t+1}, R_{M, t+1}-C_{M, t+1}\right)}{\operatorname{Var}_{t}\left(R_{M, t+1}-C_{M, t+1}\right)},
$$

where $R_{i}$ is the return of stock $i, R_{f}$ is the risk-free rate, $R_{M}$ is the market return, $C_{i}$ is the trading cost of individual stock $i, C_{M}$ is the market trading cost, and $\lambda_{i}=E_{t}\left(R_{M, t+1}-C_{M, t+1}-R_{f}\right)$ is the risk premium. By incorporating the last term on the right-hand side of Equation (1) and rearranging the equation, we can write the LCAPM more simply as:

$$
\begin{aligned}
E_{t}\left(R_{i, t+1}\right)= & R_{f, t}+E_{t}\left(C_{i, t+1}\right)+\lambda_{t} \frac{\operatorname{Cov}_{t}\left(R_{i, t+1}, R_{M, t+1}\right)}{\operatorname{Var}_{t}\left(R_{M, t+1}-C_{M, t+1}\right)}+\lambda_{t} \frac{\operatorname{Cov}_{t}\left(C_{i, t+1}, C_{M, t+1}\right)}{\operatorname{Var}_{t}\left(R_{M, t+1}-C_{M, t+1}\right)} \\
& -\lambda_{t} \frac{\operatorname{Cov}_{t}\left(R_{i, t+1}, C_{M, t+1}\right)}{\operatorname{Var}_{t}\left(R_{M, t+1}-C_{M, t+1}\right)}-\lambda_{t} \frac{\operatorname{Cov}_{t}\left(C_{i, t+1}, R_{M, t+1}\right)}{\operatorname{Var}_{t}\left(R_{M, t+1}-C_{M, t+1}\right)} .
\end{aligned}
$$

This expression shows that the security required excess return is equal to the sum of the expected illiquidity cost and four betas multiplied by the risk premium. The LCAPM therefore introduces three additional betas to the standard single CAPM, including the covariance between the asset's illiquidity and the market illiquidity, the covariance between the asset's return and the market liquidity, and the covariance between the asset's illiquidity and the market return.

Empirically, liquidity is time-varying and persistent, which means that it has positive autocorrelation (Chordia et al., 2000; Amihud, 2002; Pastor and Stambaugh, 2003; Acharya and Pedersen, 2005). The persistence of liquidity provides the foundation for predicting returns. For example, high illiquidity in the current period indicates high illiquidity in the next period, which implies a high required return (Acharya and Pederson, 2005). Given this persistence, the innovation of illiquidity, $C_{i, t}-E_{t-1}\left(C_{i, t}\right)$, is used to capture liquidity risk in the LCAPM. Under the assumption of constant conditional variances or a constant risk premium $\lambda$, the unconditional LCAPM can be written as 
$E_{t}\left(R_{i, t}-R_{f, t}\right)=E_{t}\left(C_{i, t}\right)+\lambda \beta_{i}^{1}+\lambda \beta_{i}^{2}-\lambda \beta_{i}^{3}-\lambda \beta_{i}^{4}$,

where

$\beta_{\mathrm{i}}^{1}=\frac{\operatorname{Cov}_{t}\left(R_{i, t}, R_{M, t}-E_{t-1}\left(R_{M, t}\right)\right)}{\operatorname{Var}_{t}\left(R_{M, t}-E_{t-1}\left(R_{M, t}\right)-\left[C_{M, t}-E_{t-1}\left(C_{M, t}\right)\right]\right)}$,

$\beta_{\mathrm{i}}^{2}=\frac{\operatorname{Cov}_{t}\left(C_{i, t}-E_{t-1}\left(C_{i, t}\right), C_{M, t}-E_{t-1}\left(C_{M, t}\right)\right)}{\operatorname{Var}_{t}\left(R_{M, t}-E_{t-1}\left(R_{M, t}\right)-\left[C_{M, t}-E_{t-1}\left(C_{M, t}\right)\right]\right)}$,

$\beta_{\mathrm{i}}^{3}=\frac{\operatorname{Cov}_{t}\left(R_{i, t}, C_{M, t}-E_{t-1}\left(C_{M, t}\right)\right)}{\operatorname{Var}_{t}\left(R_{M, t}-E_{t-1}\left(R_{M, t}\right)-\left[C_{M, t}-E_{t-1}\left(C_{M, t}\right)\right]\right)}$,

$\beta_{\mathrm{i}}^{4}=\frac{\operatorname{Cov}_{t}\left(C_{i, t}-E_{t-1}\left(C_{i, t}\right), R_{M, t}-E_{t-1}\left(C_{M, t}\right)\right)}{\operatorname{Var}_{t}\left(R_{M, t}-E_{t-1}\left(R_{M, t}\right)-\left[C_{M, t}-E_{t-1}\left(C_{M, t}\right)\right]\right)}$.

Equation (4) implies that the LCAPM captures market risk and three kinds of liquidity risk simultaneously. Specifically, $\beta_{i}^{1}$ is the adjusted market beta that includes transaction costs in the denominator, and it describes the movement of the security's price relative to that of the market. $\beta_{i}^{2}$ estimates the liquidity risk due to liquidity commonalities, as defined by Chordia et al. (2000), Huberman and Halka (1999), and Hasbrouck and Seppi (2001). $\beta_{i}^{3}$ estimates the risk caused by the comovement of the security's price and the market liquidity. $\beta_{i}^{4}$ captures the return's effect due to the covariance between the security's illiquidity and the market return. The sign of each beta has an economic meaning. For example, a positive sign of $\beta_{i}^{2}$ implies that investors require compensation for an illiquid security when the market is illiquid, and a negative sign of $\beta_{i}^{3}$ means that investors will accept a stock with a lower expected return when the market is liquid but expect a higher return when the market is illiquid. Because investors are willing to accept a lower expected return on a liquid security in a shrinking market, the sign of $\beta_{i}^{4}$ is expected to be negative.

To isolate the effects of liquidity and market risk, Kim and Lee (2014) define the net liquidity beta, $\beta_{i}^{5}$, as a linear combination of the three liquidity betas in the LCAPM:

$\beta_{i}^{5}=\beta_{i}^{2}-\beta_{i}^{3}-\beta_{i}^{4}$

With this definition, the LCAPM becomes

$E_{t}\left(R_{i, t}-R_{f, t}\right)=E_{t}\left(C_{i, t}\right)+\lambda \beta_{i}^{1}+\lambda \beta_{i}^{5}$.

\section{DATA AND LIQUIDITY MEASURES}

\section{Data Screening}

The data used in this study include the daily returns, daily prices, market capitalizations, book-tomarket ratios, and daily trading volumes of common shares for all firms listed on the Tokyo Stock Exchange first section from January 1983 to December 2016. The primary data source is the NIKKEI NEEDS Database. To be included in the sample, stocks are required to have at least 120 trading days in a year. They are also required to have non-negative market capitalizations and non-negative book-to-price ratios over the sample period. Because several types of events, such as stock splits or stock delistings, can affect illiquidity (Conroy et al., 1990; Goyenko et al., 2005; Kim and Lee, 2014), we exclude observations in years when splits or delistings occur. Because we investigate the effects of different liquidity measures 
on the efficiency of the LCAPM, stocks are required to have valid results for all six illiquidity measures, which are introduced in the next section. After this screening process, we have 851 sample stocks in 1983, and the number of sample stocks increases to 1,779 in 2016. In total, our data include 45,097 firm-year observations over the sample period.

\section{Illiquidity Measures}

As illustrated by Acharya and Pedersen (2005), liquidity is not an observable variable. Many proxies for liquidity, such as the bid-ask spread, are based on microstructure data and are not available over a long time horizon. Thus, inspired by Acharya and Pedersen (2005) and Kim and Lee (2014), we use illiquidity rather than liquidity measures to estimate transaction costs. ${ }^{1}$

The first illiquidity measure is that used by Acharya and Pedersen (2005), that is, the price impact measure developed by Amihud (2002):

$$
I L L I Q=\sum_{t=1}^{t} \frac{\left|r_{t}\right|}{\text { Volume }_{t}},
$$

where $r_{t}$ is the daily stock return on day $t$ and $V$ olume $e_{t}$ is the dollar trading volume on day $t$. The intuition for this measure is that it captures the daily price response associated with one dollar of trading volume (Goyenko, Holden, and Trzcinka, 2009). A stock must have positive trading volume to apply this measure because it is undefined if the dominator is zero. The monthly illiquidity is computed using the stock return and the stock trading volume in the past year.

Another price impact measure used in this study is " $\gamma$ ", developed by Pastor and Stambaugh (2003), which is calculated by running the regression

$r_{t+1}^{e}=\theta+\phi r_{t}+\gamma \operatorname{sign}\left(r_{t}^{e}\right)\left(\right.$ Volume $\left._{t}\right)+\varepsilon_{t}$,

where $r_{t}^{e}$ is the security's excess return above the market return on day $t$ and $V_{\text {olume }}$ is the trading volume in dollars on day $t$.This measure assumes that the greater the expected reversal is for a given dollar volume, the lower the stock's illiquidity is. That is, $\gamma$ is expected to be negative in general, and when liquidity is lower, the absolute magnitude of $\gamma$ is larger. The implied price impact of this measure is therefore given by the product of $\gamma$ and -1: $P S_{t}=\gamma_{t} \times(-1)$.

The third illiquidity measure is the security's turnover, which is proposed by Datar (1998) and is computed as

$\operatorname{Turn}_{t}=\frac{\text { mumber of sharestraded indayt } t}{\text { number of sharesissued }}$.

The advantage of using the turnover rate as a proxy for liquidity is the high data availability, which allows for the examination of liquidity effects across many stocks over a long period of time. We compute the monthly turnover using the previous year of data, and we refer to the turnover ratio as a measurement of the security trading quantity.

If a security's trading costs are higher than its expected trading benefits, investors will choose not to trade, leading to a zero return or zero trading volume for that observation. In other words, the absence of trade in a security indicates its degree of illiquidity; the more frequent the absence of trade is, the less liquid the security is. For these illiquid stocks, we use the turnover-adjusted zero-return measure of Liu (2006) as our fourth measure to estimate the trading speed of the illiquidity: 
$L M x_{i, t}=\left[N_{z}+\frac{\frac{1}{T V x}}{D F}\right] \times \frac{21 x}{N x}$.

where $N_{z}$ is the number of zero trading volume days, TVx is the turnover rate in the previous $x$ months, $N_{x}$ is the number of trading days in the previous $x$ months, the subscript $x$ is the estimation period in months, and $D F$ is a deflator to ensure that the second term in the square brackets falls in the range of zero to one (not inclusive) for all sample stocks. The last term in Equation (10) is used to adjust the result for comparability with the other illiquidity measures. We use twelve months as the estimate window for this measure.

Lesmond, Ogden, and Trzcinka (1999) propose an estimator of transaction costs by estimating the incidence of zero returns. This estimator is based on the assumption that the standard "market model" is correct for pricing securities but is constrained because of the effects of the transaction costs. They describe the relation between the stock "true return" and the market return as:

$R_{j t}^{*}=\beta_{j} R_{m t}+\varepsilon_{j t}$

where $R_{j t}^{*}$ is the unobserved true return of stock $j$ on day $t, \beta_{j}$ is the sensitivity of stock $j$ to the market return, $R_{m t}$ is the observed market return on day $t$, and $\varepsilon_{j t}$ is the information shock on day $t$. Furthermore, they assume that the marginal informed investors are rational and that they trade only when the excess return of stock $j$ above the market return exceeds the transaction cost. Considering a situation in which trading costs exist for stock $j$, they define $\alpha_{1 j} \leq 0$ as the seller's transaction cost and $\alpha_{2 j} \geq 0$ as the buyer's transaction cost. Then, the observed return $R_{j t}$ can be represented as:

$$
\begin{aligned}
& R_{j t}=R_{j t}^{*}-\alpha_{1 j}, \text { when } R_{j t}^{*}<\alpha_{1 j}, \\
& R_{j t}=R_{j t}^{*} \text {, when } \alpha_{1 j}<R_{j t}^{*}<\alpha_{2 j}, \\
& R_{j t}=R_{j t}^{*}+\alpha_{2 j}, \text { when } \alpha_{2 j}<R_{j t}^{*} .
\end{aligned}
$$

Given that only the ex post return of the marginal trade can be observed, all costs encountered by the marginal trader are included in the transaction costs. Thus, the measure of the total round-trip transaction costs, LOT, is defined as the difference in buyers' and sellers' trading costs:

$$
L O T=\alpha_{2 j}-\alpha_{1 j}
$$

The parameters $\alpha_{1 j}, \alpha_{2 j}$, and $\beta_{j}$ can be obtained by maximizing the logarithm of the likelihood function.

The last illiquidity proxy we employ is an estimator of the effective spread proposed by Roll (1984). In general, Roll's measure is defined as the serial covariance of price changes:

$$
R O_{i, t}=2 \sqrt{\left|\operatorname{Cov}\left(\Delta P_{t}, \Delta P_{t-1}\right)\right|}
$$

where $P_{t}$ is the last observd trade price in year $t$ and $\Delta$ is the change operator. Like other liquidity measures, $\mathrm{RO}$ is computed based on data from the past year. 
Overall, the illiquidity measures used in our study estimate five aspects of liquidity, including the price impact, the trading quantity, the trading cost, the trading speed, and the effective spread. Thus, these illiquidity measures can be representative estimators of the illiquidity of Japanese stocks.

\section{ESTIMATION OF BETAS}

Pastor and Stambaugh (2003), Acharya and Pedersen (2005), and Korajczyk and Sadka (2008) propose that investors require compensation for bearing liquidity only when the liquidity risk is systematic and persistent. Kim and Lee (2014) estimate the efficiency of the LCAPM in the US stock market using multiple illiquidity measures. To provide comparable results to those of Kim and Lee (2014) and ensure that the liquidity risks computed using all six illiquidity measures are applicable to the Japanese stock market, this analysis begins by constructing the aggregate market illiquidity and its persistence, which is consistent with Kim and Lee's (2014) analysis.

\section{Market Aggregate Illiquidity}

Many empirical studies, such as those of Amihud and Mendelson (1986) and Kim and Lee (2014), have proven that illiquidity is higher for smaller stocks and lower for larger stocks. We therefore examine the reliability of these illiquidity measures by comparing the magnitude of illiquidity across groups of different size stocks.

Table 1 reports the average of illiquidity and other properties for 25 equally weighted size portfolios. Because about ninety percent of Japanese firms' fiscal years end at the end of March and the prompt reports for these firms are released in May, we rebalance the 25 size portfolios at the end of June every year based on the market value of the equity. In this table, LnMV and BPR are the average natural logarithm of market capitalization and the average book-to-market ratio of stocks in the specified size portfolios, respectively.

The table shows that for ILLIQ, LMx, LOT, and RO, illiquidity roughly decreases as the average stock size increases, which is consistent with our expectation. However, gamma and turnover exhibit fluctuating patterns. In general, portfolios of larger stocks have lower average monthly returns and lower illiquidity levels.

To estimate the differences and commonalities of the illiquidity proxies, we compute the Pearson correlations between the market capitalization and the aggregate market illiquidity. The market capitalization is computed by taking an equally weighted average of the logarithms of the market capitalizations of individual stocks. The market aggregate illiquidity is computed by taking an equally weighted average of the stock illiquidity for the six illiquidity measures.

Table 2 reports the results of the Pearson correlation tests among the aggregate market capitalization and aggregate illiquidity measures. We find that, aside from RO, all illiquidity measures are negatively correlated with market capitalization, implying that the higher illiquidity roughly corresponds to smaller firm size. Specifically, this correlation is significant at the 1\% level for ILLIQ and LMx and at the 5\% level for turnover and LOT. Although the aggregate RO is positively correlated with market capitalization, the estimate is insignificant. We also compute the correlation between RO and market capitalization at the individual firm level as -0.1995 , which is significant at the $1 \%$ level. Thus, even for $\mathrm{RO}$, higher illiquidity is still associated with smaller firm size. 
TABLE 1 AVERAGE OF ILLIQUIDITY AND OTHER PROPERTIES FOR SIZE PORTFOLIOS

\begin{tabular}{crrrrrrrrr}
\hline Rank & Return & ILLIQ & \multicolumn{1}{c}{ Gamma } & Turnover & LMx & \multicolumn{1}{l}{ LOT } & \multicolumn{1}{l}{ RO } & \multicolumn{1}{l}{ nMV } & BPR \\
\hline 1 & 1.410 & 76.362 & -0.064 & 42.168 & 11.027 & 0.039 & 1.891 & 8.804 & 1.085 \\
2 & 1.119 & 43.964 & 0.144 & 36.200 & 8.113 & 0.033 & 1.693 & 9.213 & 1.096 \\
3 & 0.954 & 34.361 & 0.356 & 32.682 & 7.519 & 0.029 & 1.567 & 9.440 & 1.085 \\
4 & 0.856 & 27.440 & 0.150 & 30.687 & 7.577 & 0.028 & 1.496 & 9.630 & 1.060 \\
5 & 0.997 & 21.099 & 0.346 & 30.872 & 6.164 & 0.026 & 1.452 & 9.802 & 1.046 \\
6 & 0.817 & 18.017 & 0.150 & 30.606 & 5.698 & 0.024 & 1.400 & 9.949 & 1.014 \\
7 & 0.808 & 14.763 & 0.275 & 29.952 & 4.726 & 0.024 & 1.399 & 10.084 & 1.018 \\
8 & 0.713 & 12.905 & 217.184 & 27.891 & 4.683 & 0.022 & 1.373 & 10.216 & 0.963 \\
9 & 0.695 & 11.015 & 0.107 & 30.110 & 3.947 & 0.022 & 1.377 & 10.345 & 0.920 \\
10 & 0.681 & 9.684 & 172.603 & 29.522 & 4.097 & 0.021 & 1.324 & 10.469 & 0.942 \\
11 & 0.705 & 8.290 & 85.698 & 29.361 & 3.847 & 0.021 & 1.336 & 10.618 & 0.893 \\
12 & 0.673 & 7.019 & 0.087 & 29.433 & 3.480 & 0.020 & 1.319 & 10.761 & 0.886 \\
13 & 0.627 & 6.010 & 87.047 & 28.716 & 3.252 & 0.019 & 1.300 & 10.908 & 0.858 \\
14 & 0.629 & 4.763 & 86.948 & 31.062 & 2.335 & 0.018 & 1.278 & 11.052 & 0.826 \\
15 & 0.639 & 4.176 & 129.226 & 30.436 & 2.330 & 0.018 & 1.265 & 11.212 & 0.783 \\
16 & 0.597 & 3.528 & 171.692 & 28.912 & 2.016 & 0.017 & 1.239 & 11.365 & 0.784 \\
17 & 0.622 & 2.811 & 260.567 & 31.259 & 1.618 & 0.016 & 1.241 & 11.534 & 0.780 \\
18 & 0.603 & 2.479 & 86.855 & 30.680 & 1.508 & 0.016 & 1.205 & 11.712 & 0.784 \\
19 & 0.558 & 1.886 & 261.374 & 31.763 & 1.132 & 0.016 & 1.203 & 11.912 & 0.711 \\
20 & 0.578 & 1.493 & 43.138 & 35.547 & 0.956 & 0.015 & 1.211 & 12.118 & 0.692 \\
21 & 0.682 & 1.183 & 85.363 & 34.013 & 1.109 & 0.015 & 1.174 & 12.392 & 0.648 \\
22 & 0.537 & 0.784 & 43.340 & 34.538 & 0.481 & 0.014 & 1.167 & 12.676 & 0.635 \\
23 & 0.618 & 0.625 & 129.533 & 32.847 & 0.538 & 0.014 & 1.107 & 13.063 & 0.576 \\
24 & 0.593 & 0.419 & 390.610 & 31.923 & 0.476 & 0.012 & 1.081 & 13.575 & 0.576 \\
25 & 0.537 & 0.210 & 86.137 & 29.589 & 0.266 & 0.011 & 1.070 & 14.518 & 0.539 \\
\hline
\end{tabular}

Note: The gamma value is multiplied by one thousand. 
TABLE 2

\section{CORRELATION BETWEEN THE MARKET ILLIQUIDITY} AND THE ILLIQUIDITY MEASURES

\begin{tabular}{cllllll}
\hline & lnMV & ILLIQ & Gamma & Turnover & LMx & LOT \\
\hline ILLIQ & $-0.614^{* * *}$ & & & & & \\
Gamma & -0.049 & -0.177 & & & & \\
Turnover & $-0.093^{* *}$ & $-0.557^{* * *}$ & $0.383^{* * *}$ & & & \\
LMx & $-0.221^{* * *}$ & $0.430^{* * *}$ & $-0.403^{* * *}$ & $-0.502^{* * *}$ & & \\
LOT & $-0.113^{* * *}$ & $0.690^{* * *}$ & $-0.410^{* * *}$ & $-0.754^{* * *}$ & $0.679^{* * *}$ & \\
RO & 0.060 & $0.412^{* * *}$ & $-0.119^{* *}$ & $-0.391^{* * *}$ & $-0.155^{* * *}$ & $0.438^{* * *}$ \\
\hline \multicolumn{6}{c}{ The signs *,** and *** denote significance at the $10 \%, 5 \%$, and $1 \%$ levels, respectively. }
\end{tabular}

Moreover, the correlations between the six illiquidity proxies are significant at the $1 \%$ level in all cases. Among the six illiquidity proxies, ILLIQ, LOT, LMx, and RO are positively correlated with each other, whereas turnover and gamma are positively correlated with each other but are negatively correlated with the other four illiquidity proxies. The highest positive correlation among the illiquidity proxies is 0.679 for ILLIQ and LOT, and the lowest negative correlation is -0.754 for turnover and LOT. The Pearson correlation test provides an explanation for the different patterns of the six illiquidity proxies in the size-based portfolios. These notable differences motivate our empirical analysis testing the efficiency of the LCAPM using different illiquidity measures.

\section{Illiquidity Innovations}

As demonstrated by the previous literature (Pastor and Stambaugh, 2003; Acharya and Pedersen, 2005; Kim and Lee, 2014), the market aggregation of illiquidity is highly persistent. We compute the first-order autocorrelations of market illiquidity for the six proxies for illiquidity using Japanese stock data. The autocorrelations vary from 0.996 for ILLIQ to 0.744 for gamma. Therefore, we use the innovation of illiquidity, which is the residual term of the autoregressive model, to examine liquidity risk. Because Acharya and Pedersen (2005) and Kim and Lee (2014) use an ex-post AR(2) model to obtain the market illiquidity innovation, we use the same simple model to compute the market return and illiquidity innovations. The autoregressive model we use is given as:

$$
C_{M, t}=\rho_{0}+\rho_{1} C_{M, t-1}+\rho_{2} C_{M, t-2}+\mu_{M, t}
$$

Figure 1 plots the time series of the market aggregate illiquidity innovation.

However, after checking the autocorrelation and partial autocorrelation plots, we find that $\operatorname{AR}(2)$ is not the best fitting time-series model for each individual stock. Following the Box-Jenkins method, we use the autoregressive integrated moving average (ARIMA) model to plot the innovations of illiquidity and of stock returns. The standard ARIMA model is shown as:

$$
\left(1-\sum_{i=1}^{p} \alpha_{i} L^{i}\right) X_{t}=\left(1-\sum_{i=1}^{q} \theta_{i} L^{i}\right) \varepsilon_{t}
$$

where $L$ is the lag operator, $\alpha_{i}$ is the coefficient of the autoregressive part of the model, $\theta_{i}$ is the coefficient of the moving average part of the model, and the residual term $\varepsilon_{t}$ is the innovation of the illiquidity. 
FIGURE 1

TIME-SERIES PLOTS OF INNOVATIONS OF MARKET AGGREGATE ILLIQUIDITY
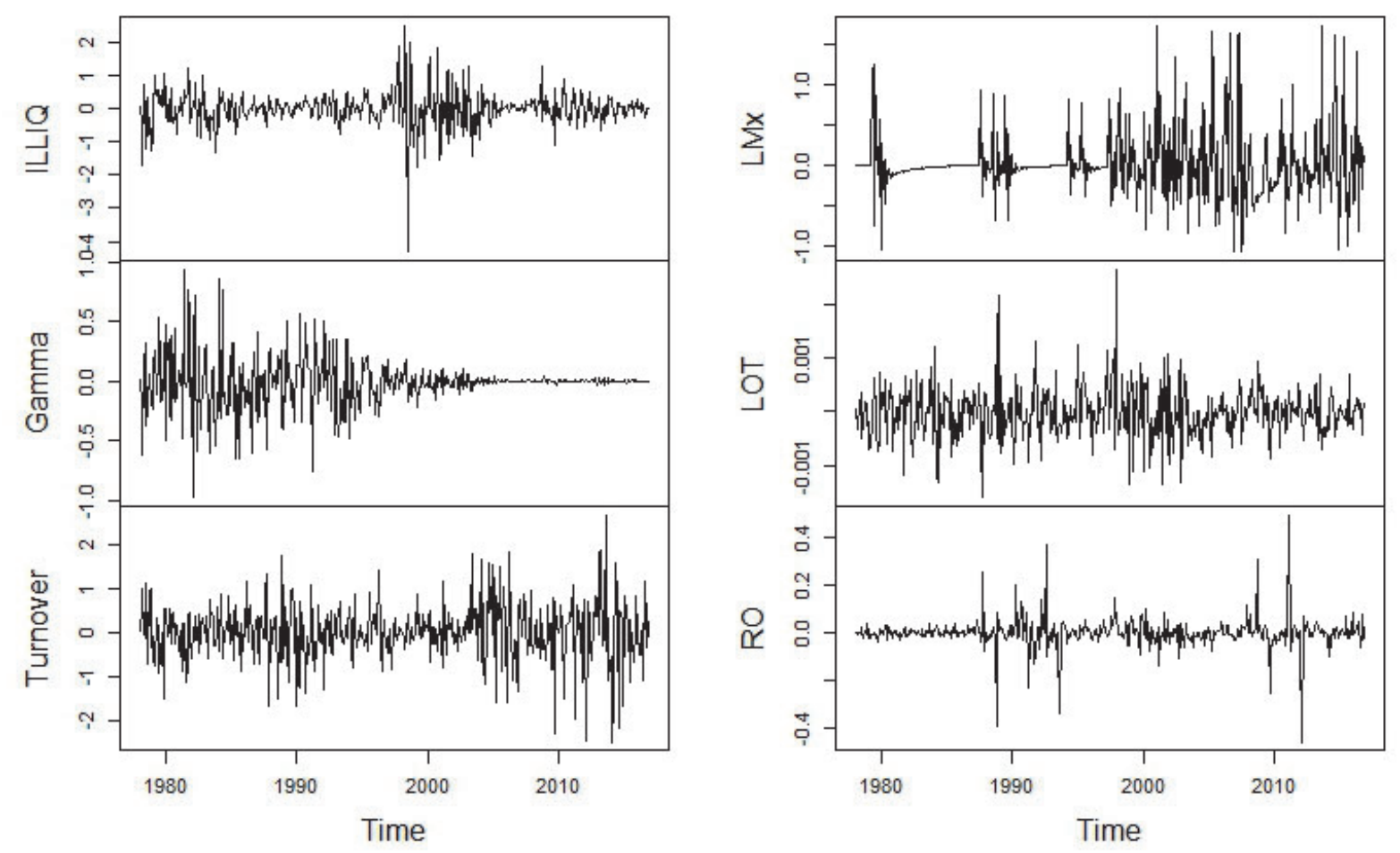

\section{Estimation of Beta}

To provide comparable results to those of Kim and Lee (2014), we estimate liquidity risk at the portfolio level and use individual stocks as test assets in the regression stage.

The detailed procedure is as follows:

1. We estimate innovations of illiquidity for an individual stock , $C_{i, t}-E_{t-1}\left(C_{i, t}\right)$; innovations of market aggregate illiquidity, $C_{M, t}-E_{t-1}\left(C_{M, t}\right)$; and innovations of the market return, $R_{M, t}-E_{t-1}\left(R_{M, t}\right)$.

2. We estimate the pre-ranking beta $k(k=1,2,3,4)$ for stock $i$ in each month according to Equation (4) using monthly stock returns, innovations of illiquidity, and innovations of the market return within a five-year estimation window.

3. We form ten equally weighted test portfolios sorted by the estimated pre-ranking beta $k$, and we rebalance the portfolios every year.

4. For each test portfolio $p$, we estimate the innovations of illiquidity, $C_{p, t}-E_{t-1}\left(C_{p, t}\right)$.

5. Using these innovations of illiquidity and returns, we estimate the post-ranking beta $k$ of portfolio $p$ over the sample period using Equation (4).

6. We assign the post-ranking beta $k$ to all stocks that belong to portfolio $p$ in a given year.

7. When a stock obtains all four liquidity betas, we compute the net liquidity beta using Equation (5).

8. The resulting post-ranking betas of ten equally weighted portfolios sorted by their corresponding pre-ranking betas are presented in Table 3 . We can see rough monotonic patterns in the post-ranking betas of these portfolios.

In addition, we estimate the liquidity risk for characteristic-based portfolios and use these portfolios as test assets to construct cross-sectional regressions. 
TABLE 3

POST-RANKING BETAS OF TEN EQUALLY WEIGHTED PORTFOLIOS SORTED BY CORRESPONDING PRE-RANKING BETAS

\begin{tabular}{|c|c|c|c|c|c|c|c|c|}
\hline Rank & Beta1 & Beta2 & Beta3 & Beta4 & Beta1 & Beta2 & Beta3 & Beta4 \\
\hline \multicolumn{4}{|c|}{ Panel A. Amihud (ILLIQ) } & & \multicolumn{4}{|c|}{ Panel B. Pastor and Stambaugh (Gamma) } \\
\hline 1 & 0.6349 & 0.0003 & -0.0409 & -0.0663 & 0.6723 & 0.1432 & 0.0038 & -0.0794 \\
\hline 2 & 0.7081 & 0.0006 & -0.0356 & -0.0557 & 0.7499 & -0.1743 & 0.0029 & -2.7493 \\
\hline 3 & 0.7887 & 0.0010 & -0.0330 & -0.0351 & 0.8334 & 0.1679 & 0.0031 & -7.0213 \\
\hline 4 & 0.8177 & 0.0018 & -0.0333 & -0.0197 & 0.8683 & 0.1070 & 0.0021 & -1.0744 \\
\hline 5 & 0.8808 & 0.0034 & -0.0310 & -0.0133 & 0.9336 & 0.1792 & 0.0023 & 1.7951 \\
\hline 6 & 0.9262 & 0.0054 & -0.0300 & -0.0127 & 0.9806 & 0.0416 & 0.0021 & -2.4740 \\
\hline 7 & 0.9404 & 0.0037 & -0.0278 & -0.0043 & 0.9945 & 0.5833 & 0.0034 & 1.8327 \\
\hline 8 & 1.0395 & 0.0067 & -0.0247 & -0.0032 & 1.0994 & 0.0349 & 0.0021 & 1.3060 \\
\hline 9 & 1.0631 & 0.0125 & -0.0218 & -0.0011 & 1.1325 & 0.8158 & 0.0029 & -21.2771 \\
\hline \multirow[t]{2}{*}{10} & 1.1565 & 0.0447 & -0.0215 & -0.0167 & 1.2227 & -1.3997 & 0.0033 & -10.0641 \\
\hline & \multicolumn{4}{|c|}{ Panel C. Datar (Turnover) } & \multicolumn{4}{|c|}{ Panel D. Liu (LMx) } \\
\hline 1 & 0.6273 & 0.0182 & -0.0498 & -0.0491 & 0.6643 & 0.0007 & -0.0092 & -0.0119 \\
\hline 2 & 0.7008 & 0.0046 & -0.0447 & -0.0387 & 0.7403 & 0.0003 & -0.0080 & -0.0138 \\
\hline 3 & 0.7786 & 0.0046 & -0.0394 & -0.0248 & 0.8247 & 0.0001 & -0.0084 & -0.0059 \\
\hline 4 & 0.8097 & 0.0051 & -0.0363 & -0.0265 & 0.8583 & 0.0001 & -0.0082 & -0.0012 \\
\hline 5 & 0.8712 & 0.0076 & -0.0364 & -0.0248 & 0.9228 & 0.0002 & -0.0079 & -0.0016 \\
\hline 6 & 0.9146 & 0.0084 & -0.0352 & -0.0378 & 0.9689 & 0.0004 & -0.0075 & -0.0012 \\
\hline 7 & 0.9267 & 0.0099 & -0.0331 & -0.0241 & 0.9855 & 0.0006 & -0.0080 & -0.0029 \\
\hline 8 & 1.0276 & 0.0113 & -0.0330 & -0.0295 & 1.0860 & 0.0009 & -0.0077 & 0.0014 \\
\hline 9 & 1.0610 & 0.0163 & -0.0295 & -0.0322 & 1.1156 & 0.0012 & -0.0076 & -0.0017 \\
\hline \multirow[t]{2}{*}{10} & 1.1372 & 0.0496 & -0.0295 & -0.0470 & 1.2118 & 0.0020 & -0.0066 & -0.0198 \\
\hline & \multicolumn{4}{|c|}{ Panel E Lesmond et al. (LOT) } & \multicolumn{4}{|c|}{ Panel F. Roll (RO) } \\
\hline 1 & 0.6731 & 0.0072 & 1.9629 & 2.6097 & 0.6715 & 0.0001 & -0.0019 & -0.0011 \\
\hline 2 & 0.7512 & 0.0052 & 1.5793 & 1.0633 & 0.7498 & 0.0001 & -0.0015 & -0.0008 \\
\hline 3 & 0.8357 & 0.0062 & 1.6376 & 7.3818 & 0.8354 & 0.0001 & -0.0015 & -0.0011 \\
\hline 4 & 0.8685 & 0.0060 & 1.3089 & 7.8742 & 0.8650 & 0.0001 & -0.0013 & -0.0012 \\
\hline 5 & 0.9345 & 0.0076 & 1.4766 & 16.2101 & 0.9314 & 0.0001 & -0.0013 & -0.0011 \\
\hline 6 & 0.9835 & 0.0073 & 0.8476 & -3.4965 & 0.9825 & 0.0001 & -0.0013 & -0.0006 \\
\hline 7 & 0.9977 & 0.0068 & 1.8625 & 0.8604 & 0.9960 & 0.0001 & -0.0014 & -0.0006 \\
\hline 8 & 1.1026 & 0.0074 & 2.1730 & 5.5390 & 1.0991 & 0.0002 & -0.0014 & -0.0015 \\
\hline 9 & 1.1328 & 0.0091 & 2.4375 & 6.8743 & 1.1304 & 0.0002 & -0.0013 & -0.0011 \\
\hline 10 & 1.2260 & 0.0115 & 2.3682 & -4.4877 & 1.2235 & 0.0002 & -0.0017 & -0.0008 \\
\hline
\end{tabular}

Note: Beta 2 in Panels B and E, beta 3 in Panel E, and beta 4 in Panels B and E are multiplied by one million.

\section{EMPIRICAL RESULTS}

In this section, we study the efficiency of the LCAPM in the Japanese market. We run cross-sectional regressions at both the individual stock level and the characteristic-based portfolio level, and we compare the adjusted R-squared values to evaluate the performance of the LCAPM for different test assets.

\section{Cross-sectional Regressions Using Stock Returns and Post-ranking Betas}

Following Acharya and Pederson (2005) and Kim and Lee (2014), we consider special cases of the relation 
$E\left(R_{i, t}-R_{f, t}\right)=a+b E\left(C_{i, t}\right)+\lambda \beta_{i}^{1}+\lambda \beta_{i}^{2}+\lambda \beta_{i}^{3}+\lambda \beta_{i}^{4}+\lambda \beta_{i}^{5}$,

where $E\left(C_{i, t}\right)$ is the expected average monthly illiquidity over the previous twelve months.

We also include the $\log$ of market capitalization and the $\log$ of the book-to-market ratio in the regression to examine the specification of the model (Kim and Lee, 2014). Both the log of market capitalization and the log of the book-to-market ratio are estimated at the end of June in year $t$.

To compare our results to those of Kim and Lee (2014), we first run cross-sectional regressions at the stock level using stock returns and the estimated post-ranking betas. We test the null hypothesis of a zero illiquidity premium against the alternative hypothesis of a positive illiquidity premium. If the LCAPM holds, the intercept of this regression should not be significantly different from zero, whereas the coefficients on the liquidity betas should be significantly different from zero. We use Student's t-test to examine the significance level of the factor $\beta$ :

$$
t=\frac{{\text { average }\left(\text { Coefficient }_{i, \beta}\right)}}{\sqrt{\sigma^{2}\left(\text { Coefficient }_{i, \beta}\right)}} \times \sqrt{\text { the amount of } i} .
$$

The adjusted $R^{2}$ is computed by taking the average of each single cross-sectional regression. Table 4 shows the results for the cross-sectional regression at the stock level.

For the combined LCAPM, which includes liquidity risk as well as size and the book-to-market ratio, the order of the illiquidity proxies from highest to lowest according to the adjusted R-squared is turnover, LOT, ILLIQ, LMx, RO, and gamma. For the single LCAPM, the order of the illiquidity proxies from highest to lowest according to the adjusted R-squared is LOT, turnover, ILLIQ, RO, LMx, and gamma. Comparing the two models, the adjusted R-squared of the combined LCAPM is about two times that of the single LCAPM, which means that size and the book-to-market ratio have substantial explanatory power. The highest adjusted R-squared in Table 4, that is, 9.1\%, occurs in the combined LCAPM, in which the turnover ratio is used as the liquidity proxy and all four liquidity betas are used as independent variables. The second highest adjusted R-squared still occurs with the turnover proxy, which takes the single risk beta 3 as the independent liquidity variable, and is about 8.8\%. Because Acharya and Pedersen (2005) show that the collinearity problems between the liquidity risk proxies are severe, we focus more on the regressions that use a single liquidity risk, and we only consider beta 5 as a signal of the existence of liquidity risk. In panels A, B, C, D, and F, beta 5 is significant in combined LCAPM, proving that the liquidity risk is significantly priced in the Japanese stock market, and, thus, that the sources of the liquidity risk need further investigation.

Comparing the single LCAPM and the combined LCAPM, Table 4 shows that the significance levels of transaction costs and liquidity risks increase if market capitalization and the book-to-market ratio are incorporated in the model. Specifically, in the combined LCAPM, beta 2 is significant based on ILLIQ, gamma, turnover rate, LMx, and LOT; beta 3 is significant based on ILLIQ, gamma, the turnover rate and LOT; and beta 4 is significant based on ILLIQ, gamma, and LOT. However, those liquidity betas are seldom significant in the single LCAPM. Thus, we infer that both the market capitalization and the bookto-market ratio are related to the stock return. When we control for the effects of these variables on the stock return, the effects of the liquidity betas become significant, meaning that liquidity risk factors are priced in Japan. Although the single LCAPM does not work well in Japan, the combined LCAPM might work well, and, thus, we suggest that the size and value factor should be considered together when studying the pricing of liquidity risk. To provide detailed evidence, we report regression results for both the single and the combined LCAPM.

In conclusion, different liquidity measures have different explanatory powers and are sensitive to different sources of liquidity risk. However, according to beta 5, we obtain a unified conclusion that liquidity risk is generally significantly priced in the Japanese stock market. We further identify the sources of liquidity risk and find that liquidity risk is sensitive to the liquidity measure. In general, we 
suggest using the combined LCAPM, Amihud's ILLIQ, the turnover ratio, and Lesmond, Ogden, and Trzcinka's LOT to estimate Japanese stock returns, given the explanatory power of the model and the significances of the liquidity betas. To further verify these results and comprehensively estimate the efficiency of the LCAPM, we run cross-sectional regressions at the portfolio level using a similar process to that used at the stock level.

TABLE 4

CROSS-SECTIONAL REGRESSIONS USING INDIVIDUAL STOCK AS TEST ASSETS

\begin{tabular}{|c|c|c|c|c|c|c|c|c|c|}
\hline Int. & Illiq & Beta1 & Beta2 & Beta3 & Beta4 & Beta5 & $\operatorname{lnMV}$ & $\operatorname{lnBM}$ & $\operatorname{Adj} . R^{2}$ \\
\hline \multicolumn{10}{|c|}{ Panel A. Amihud (ILLIQ) } \\
\hline$-3.683^{* *}$ & $0.031^{*}$ & -0.336 & & & & 7.640 & $0.286^{*}$ & $-1.612^{* * *}$ & 0.083 \\
\hline$-2.756^{* * *}$ & $0.035^{* * *}$ & -0.142 & $5.545^{* * *}$ & & & & $0.221^{* * *}$ & $-1.636^{* * *}$ & 0.082 \\
\hline$-2.791^{* * *}$ & $0.038^{* * *}$ & -0.338 & & $-10.899^{*}$ & & & $0.212^{* * *}$ & $-1.649^{* * *}$ & 0.084 \\
\hline$-3.704^{* * *}$ & $0.032^{* * *}$ & -0.191 & & & $-11.680^{* * *}$ & & $0.293^{* * *}$ & $-1.619^{* * *}$ & 0.084 \\
\hline$-3.875^{* * *}$ & $0.032^{* * *}$ & -0.375 & -1.955 & -9.230 & $-12.274^{* * *}$ & & $0.298^{* * *}$ & $-1.620^{* * *}$ & 0.087 \\
\hline 0.679 & $0.009^{*}$ & -0.167 & & & & 0.722 & & & 0.044 \\
\hline $0.708^{*}$ & 0.008 & -0.164 & 1.551 & & & & & & 0.042 \\
\hline 0.642 & 0.007 & -0.382 & & -9.026 & & & & & 0.043 \\
\hline $0.710^{*}$ & $0.009^{*}$ & -0.167 & & & -0.342 & & & & 0.043 \\
\hline 0.597 & 0.009 & -0.322 & 0.461 & -8.276 & -0.429 & & & & 0.048 \\
\hline \multicolumn{10}{|c|}{ Panel B. Pastor and Stambaugh (Gamma) } \\
\hline 0.231 & $28.972^{*}$ & -0.369 & & & & 163.415 & 0.038 & $-1.684^{* * *}$ & 0.075 \\
\hline-0.304 & $26.935^{* *}$ & -0.389 & $-132.060^{* * *}$ & & & & 0.048 & $-1.666^{* * *}$ & 0.075 \\
\hline 0.227 & $28.964^{* *}$ & -0.370 & & $-161.077^{* * *}$ & & & 0.037 & $-1.684^{* * *}$ & 0.075 \\
\hline-0.607 & $26.661^{* *}$ & -0.371 & & & $-19.819^{* * *}$ & & 0.066 & $-1.664^{* * *}$ & 0.075 \\
\hline-0.307 & $26.354^{* *}$ & -0.315 & $-130.025^{* * *}$ & $-157.546^{* * *}$ & $-18.957^{* * *}$ & & 0.074 & $-1.675^{* * *}$ & 0.077 \\
\hline $1.095^{* *}$ & 16.060 & -0.335 & & & & 43.097 & & & 0.030 \\
\hline $0.970^{* *}$ & 14.103 & -0.326 & -66.862 & & & & & & 0.031 \\
\hline $1.094^{* *}$ & 16.056 & -0.335 & & -42.443 & & & & & 0.030 \\
\hline $0.944^{* *}$ & 14.569 & -0.325 & & & -5.546 & & & & 0.031 \\
\hline $1.028^{* *}$ & 13.986 & -0.282 & -60.555 & -42.391 & -4.691 & & & & 0.033 \\
\hline \multicolumn{10}{|c|}{ Panel C. Datar (Turnover) } \\
\hline-0.120 & $0.018^{*}$ & 0.139 & & & & -1.923 & 0.025 & $-1.867^{* * *}$ & 0.087 \\
\hline-0.360 & $0.019^{* * *}$ & 0.096 & $9.337^{* *}$ & & & & 0.026 & $-1.872^{* * *}$ & 0.088 \\
\hline 0.311 & $0.018^{* * *}$ & -0.077 & & $13.357^{* * *}$ & & & 0.033 & $-1.868^{* * *}$ & 0.088 \\
\hline-0.204 & $0.018^{* * *}$ & 0.130 & & & 1.726 & & 0.024 & $-1.869^{* * *}$ & 0.087 \\
\hline 0.138 & $0.019^{* * *}$ & -0.085 & 6.873 & $11.188^{* *}$ & 0.713 & & 0.037 & $-1.873^{* * *}$ & 0.091 \\
\hline $1.033^{* *}$ & $0.008^{* * *}$ & -0.155 & & & & -0.705 & & & 0.042 \\
\hline $0.888^{* *}$ & $0.008^{* * *}$ & -0.188 & $9.4011^{*}$ & & & & & & 0.044 \\
\hline $1.390^{* * *}$ & $0.008^{* * *}$ & -0.259 & & 8.753 & & & & & 0.045 \\
\hline $0.962^{* *}$ & $0.008^{* * *}$ & -0.128 & & & 0.297 & & & & 0.042 \\
\hline $1.195^{* *}$ & $0.008^{* * *}$ & -0.224 & 6.988 & 6.700 & -0.250 & & & & 0.048 \\
\hline
\end{tabular}

(continued on next page) 
(continued)

\begin{tabular}{|c|c|c|c|c|c|c|c|c|c|}
\hline Int. & Illiq & Beta1 & Beta2 & Beta3 & Beta4 & Beta5 & $\operatorname{lnMV}$ & $\operatorname{lnBM}$ & $\operatorname{Adj} . R^{2}$ \\
\hline \multicolumn{10}{|c|}{ Panel D. Liu (LM12) } \\
\hline-1.274 & 0.041 & -0.252 & & & & $21.111^{* * *}$ & 0.091 & $-1.678^{* * *}$ & 0.081 \\
\hline-1.360 & 0.036 & -0.214 & $329.048^{* * *}$ & & & & 0.105 & $-1.673^{* * *}$ & 0.081 \\
\hline-0.866 & $0.074^{* *}$ & -0.378 & & -43.090 & & & 0.062 & $-1.679^{* * *}$ & 0.080 \\
\hline-1.034 & 0.044 & -0.243 & & & $-20.232^{* * *}$ & & 0.085 & $-1.680^{* * *}$ & 0.081 \\
\hline$-1.806^{*}$ & 0.024 & -0.228 & $277.749^{* * *}$ & -30.505 & $-11.458^{* * *}$ & & $0.122^{*}$ & $-1.670^{* * *}$ & 0.085 \\
\hline $0.961^{* *}$ & -0.024 & -0.343 & & & & 1.162 & & & 0.036 \\
\hline $0.943^{* *}$ & -0.023 & -0.335 & 44.646 & & & & & & 0.037 \\
\hline 0.776 & -0.011 & -0.336 & & -24.623 & & & & & 0.036 \\
\hline $0.977^{* *}$ & -0.022 & -0.347 & & & -0.650 & & & & 0.036 \\
\hline 0.738 & -0.027 & -0.331 & 60.414 & -25.602 & 1.798 & & & & 0.041 \\
\hline \multicolumn{10}{|c|}{ Panel E. Lesmond et al. (LOT) } \\
\hline$-1.762^{*}$ & $14.467^{* *}$ & -0.228 & & & & -2.480 & $0.129^{*}$ & $-1.609^{* * *}$ & 0.084 \\
\hline-1.502 & $14.930^{* * *}$ & -0.204 & $-29.033^{* *}$ & & & & $0.122^{*}$ & $-1.620^{* * *}$ & 0.085 \\
\hline-1.338 & $14.797^{* * *}$ & -0.210 & & $-238.157^{* * *}$ & & & $0.127^{*}$ & $-1.623^{* * *}$ & 0.085 \\
\hline$-1.768^{*}$ & $14.540^{* *}$ & -0.224 & & & 4.001 & & $0.129^{*}$ & $-1.609^{* * *}$ & 0.084 \\
\hline-1.203 & $15.290^{* * *}$ & -0.169 & $-24.859^{*}$ & $-224.236^{* * *}$ & 3.043 & & $0.123^{*}$ & $-1.630^{* * *}$ & 0.086 \\
\hline $0.891^{* *}$ & 1.787 & -0.362 & & & & -0.928 & & & 0.045 \\
\hline $0.960^{* *}$ & 2.188 & -0.341 & -12.305 & & & & & & 0.046 \\
\hline $1.071^{* *}$ & 1.832 & -0.338 & & $-112.334^{* *}$ & & & & & 0.046 \\
\hline $0.887^{* *}$ & 1.812 & -0.360 & & & 1.633 & & & & 0.045 \\
\hline $1.104^{* *}$ & 2.139 & -0.304 & -11.652 & $-105.996^{* *}$ & 1.295 & & & & 0.047 \\
\hline \multicolumn{10}{|c|}{ Panel F. Roll (RO) } \\
\hline 0.394 & $-0.184^{* * *}$ & -0.314 & & & & $-96.750^{*}$ & 0.017 & $-1.709^{* * *}$ & 0.080 \\
\hline 0.166 & $-0.187^{* * *}$ & -0.358 & 27.822 & & & & 0.018 & $-1.709^{* * *}$ & 0.081 \\
\hline 0.399 & $-0.186^{* * *}$ & -0.300 & & 184.856 & & & 0.017 & $-1.710^{* * *}$ & 0.081 \\
\hline 0.231 & $-0.185^{* * *}$ & -0.345 & & & 59.378 & & 0.017 & $-1.706^{* * *}$ & 0.079 \\
\hline 0.454 & $-0.186^{* * *}$ & -0.305 & 69.602 & 194.062 & 60.007 & & 0.018 & $-1.712^{* * *}$ & 0.082 \\
\hline $1.087^{* *}$ & -0.047 & -0.270 & & & & -49.710 & & & 0.039 \\
\hline $0.871^{*}$ & -0.058 & -0.261 & 678.224 & & & & & & 0.040 \\
\hline $1.059^{\text {** }}$ & -0.048 & -0.301 & & 48.200 & & & & & 0.040 \\
\hline $1.018^{* *}$ & -0.048 & -0.276 & & & 54.348 & & & & 0.038 \\
\hline $1.028^{*}$ & -0.057 & -0.278 & 627.729 & 55.681 & 54.746 & & & & 0.042 \\
\hline
\end{tabular}

The signs $* * *$, and $* * *$ denote significance at the $10 \%, 5 \%$, and $1 \%$ levels, respectively.

Note: The coefficients on beta 2 and beta 4 in Panel B are divided by one thousand, the coefficients on beta 2 in Panel $\mathrm{E}$ are divided by one million, and the coefficients on beta 3 and beta 4 are divided by one thousand.

\section{Cross-sectional Regressions at the Portfolio Level}

In this subsection, we run monthly cross-sectional regressions using characteristic portfolios as test assets. We consider ten size portfolios, ten size and book-to-market (size-B/M) portfolios, and ten illiquidity portfolios sorted by each illiquidity proxy. Each portfolio is rebalanced annually. For the size and size-B/M portfolios, we estimate the liquidity beta $k(k=1,2,3,4,5)$ using portfolio returns and innovations of illiquidity for each illiquidity proxy. For the illiquidity portfolios, we estimate the 
illiquidity betas using portfolio returns and the innovations of illiquidity for the corresponding illiquidity proxy.

To sum up, the pricing of liquidity risk varies across illiquidity measures and test assets. We do not report the detailed table to conserve space. However, we find some uniform conclusions. First, the liquidity risk estimated by gamma has the lowest explanatory power in the model, which is consistent with the regressions at the stock level. Second, market capitalization and the book-to-market ratio have significant impacts on the pricing of liquidity risk. Third, no liquidity betas can be priced in liquidity portfolios. Given the sensitivity of the results to the test portfolio (Brennan et al., 1998; Berk, 2000), we mainly focus on the tests based on individual stocks as test assets.

\section{Cross-sectional Regressions Based on Principal Component Analysis}

Korajczyk and Sadka (2008) find the existence of a common component across different measures of liquidity using the PCA framework. They show that this systematic common component is accompanied by a significant liquidity premium, whereas the measure-specific liquidity is not. In this subsection, we extract common components from the six illiquidity measures using the PCA framework and then repeat the cross-sectional regressions test based on these common components.

Figure 2 shows the eigenvalues of the six principal components as well as their cumulative proportions. The principal components are computed based on the covariance matrix of the six illiquidity measures. The bar chart corresponds to the proportion of each principal component and is measured on the left axis. The line graph is the cumulative proportion and is measured on the right axis. According to Figure 2, the first two principal components can explain $54.55 \%$ of the variation across all illiquidity proxies, proving the existence of systematic and common components of the illiquidity measures.

We also estimate the Pearson correlations between the principal components and the six illiquidity proxies, as shown in Table 5. The results indicate that different components may emphasize different aspects of illiquidity. For example, the first component is highly correlated with LOT and ILLIQ, which focus on the trading cost and the price impact, respectively. The second component is highly correlated with turnover and, thus, tends to estimate the trading quantity of the security.

FIGURE 2

\section{EIGENVALUE PROPORTIONS OF PRINCIPAL COMPONENTS}

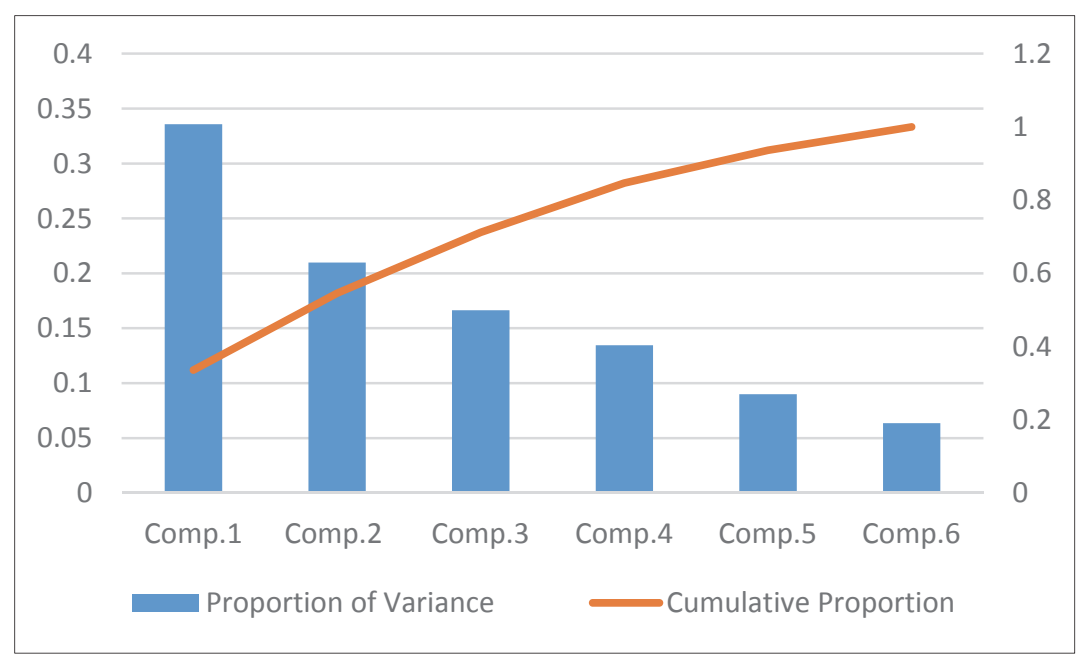


TABLE 5

CORRELATION BETWEEN THE PRINCIPAL COMPONENTS

AND THE ILLIQUIDITY MEASURES

\begin{tabular}{ccrrrrrr}
\hline & Dimension & Comp.1 & Comp.2 & Comp.3 & Comp.4 & Comp.5 & Comp.6 \\
\hline ILLIQ & Price Impact & -0.7699 & 0.2231 & -0.0101 & 0.5929 & 0.5929 & 0.0725 \\
Gamma & Price Impact & 0.0036 & -0.0792 & -0.9968 & -0.0111 & 0.0054 & -0.0051 \\
Turnover & Trading Quantity & 0.0428 & -0.7534 & 0.0405 & -0.6362 & 0.1554 & -0.0058 \\
LMx & Trading Speed & -0.5650 & 0.5172 & -0.0467 & -0.5248 & -0.3022 & 0.2106 \\
LOT & Trading Cost & -0.8518 & -0.1631 & 0.0135 & 0.0403 & -0.1917 & -0.4575 \\
RO & Effictive Spread & -0.6127 & -0.5837 & 0.0340 & 0.3527 & -0.1889 & 0.3503 \\
\hline
\end{tabular}

All results are significant at the $1 \%$ level.

Figure 3 shows the scree plot of the eigenvalues of principal components. This parallel analysis suggests using the first two components to represent the original illiquidity measures. Thus, we combine the first two principal components as a new measure of illiquidity and infer that the trading cost, the price impact, and the trading quantity are the most important liquidity dimensions in the Japanese stock market. This inference is consistent with the results of cross-sectional regressions at the stock level.

Based on the first two principal components across the six illiquidity measures, we compute the liquidity betas of the individual stocks using the procedure described in Section 4.3. Subsequently, we construct portfolios sorted by these new pre-ranking betas and compute post-ranking betas of these new portfolios. Table 6 shows the result of post-ranking betas of these ten equally weighted portfolios. Finally, we assign these post-ranking betas to corresponding individual stocks and again run cross-sectional regressions using the individual stocks as test assets.

FIGURE 3

\section{SCREE PLOT OF THE EIGENVALUES OF PRINCIPAL COMPONENTS}

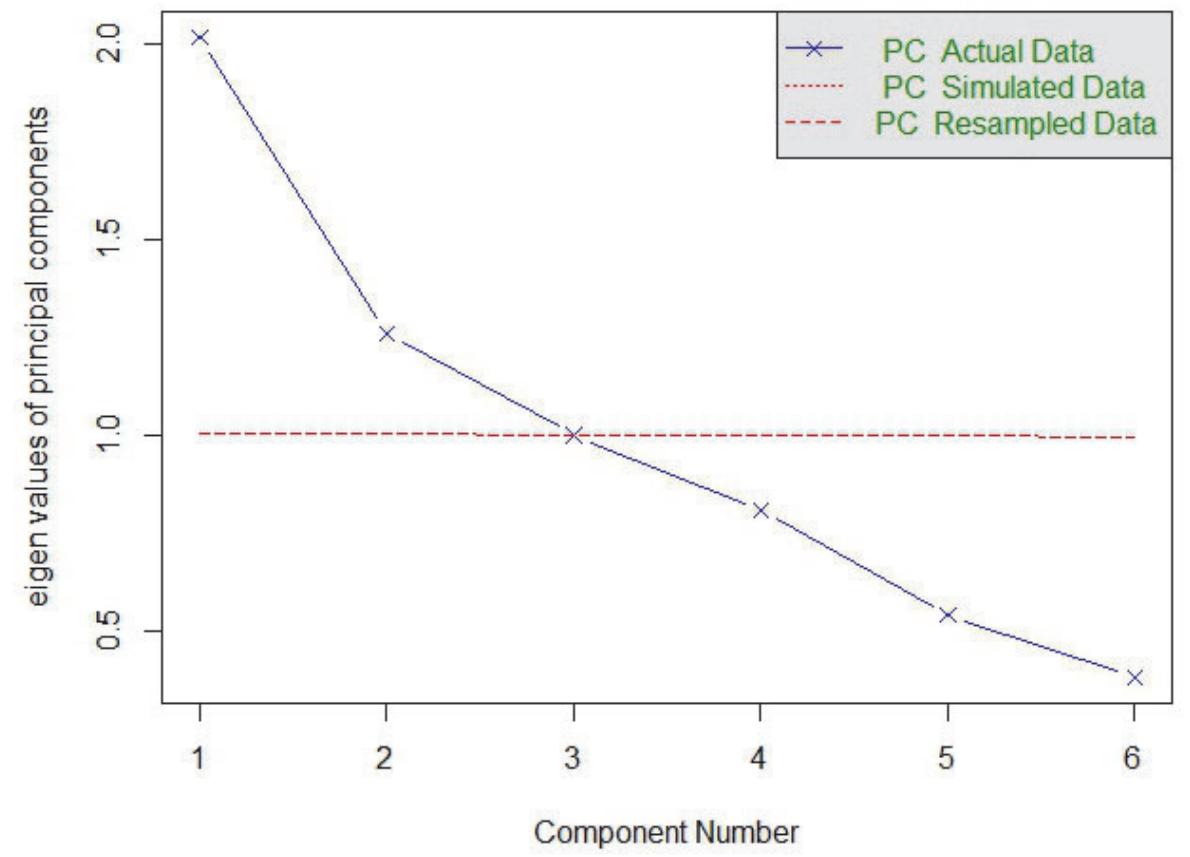


TABLE 6

POST-RANKING BETAS OF TEN EQUALLY-WEIGHTED PORTFOLIOS SORTED BY PRINCIPAL COMPONENTS

\begin{tabular}{crrrr}
\hline Rank & \multicolumn{1}{c}{ Beta1 } & \multicolumn{1}{c}{ Beta2 } & \multicolumn{1}{c}{ Beta3 } & \multicolumn{1}{c}{ Beta4 } \\
\hline 1 & 0.6713 & -0.0010 & 0.0009 & 0.0604 \\
2 & 0.7522 & -0.0004 & 0.0021 & 0.0298 \\
3 & 0.8341 & 0.0001 & 0.0029 & 0.0343 \\
4 & 0.8690 & 0.0005 & 0.0031 & 0.0263 \\
5 & 0.9313 & 0.0003 & 0.0039 & 0.0438 \\
6 & 0.9815 & 0.0003 & 0.0038 & 0.0349 \\
7 & 0.9955 & 0.0005 & 0.0049 & 0.0372 \\
8 & 1.1016 & 0.0003 & 0.0060 & 0.0326 \\
9 & 1.1295 & 0.0004 & 0.0065 & 0.0356 \\
10 & 1.2237 & -0.0002 & 0.0082 & 0.0668 \\
\hline
\end{tabular}

TABLE 7

CROSS-SECTIONAL REGRESSIONS OF PRINCIPAL COMPONENTS

\begin{tabular}{llllllllll}
\hline Int. & Illiq & Beta1 & Beta2 & Beta3 & Beta & Beta5 & lnMV & lnBM & Adj. $R^{2}$ \\
\hline-0.827 & $-0.042^{* * *}$ & $0.028^{* * *}$ & & & & 0.522 & 0.035 & $-1.796^{* * *}$ & 0.083 \\
-1.292 & $-0.042^{* * *}$ & $0.028^{* *}$ & 0.194 & & & & 0.064 & $-1.769^{* * *}$ & 0.082 \\
-0.853 & $-0.043^{* * *}$ & $0.028^{* * *}$ & & $-141.637^{* * *}$ & & & 0.040 & $-1.793^{* * *}$ & 0.083 \\
-1.349 & $-0.042^{* * *}$ & $0.027^{* * *}$ & & & $59.617^{* * *}$ & & 0.061 & $-1.796^{* * *}$ & 0.086 \\
-1.682 & $-0.043^{* * *}$ & $0.027^{* *}$ & 0.008 & $-126.351^{* * *}$ & $57.891^{* * *}$ & & 0.093 & $-1.763^{* * *}$ & 0.101 \\
$0.509^{* *}$ & $-0.039^{* * *}$ & $0.035^{* * *}$ & & & & 1.684 & & & 0.034 \\
$0.680^{*}$ & $-0.039^{* * *}$ & $0.035^{* *}$ & -0.108 & & & & & & 0.054 \\
$0.587^{* *}$ & $-0.040^{* * *}$ & $0.035^{* * *}$ & & $-175.132^{* *}$ & & & & & \\
$0.456^{* *}$ & $-0.039^{* * *}$ & $0.035^{* * *}$ & & & 27.494 & & & & 0.034 \\
$0.595^{* *}$ & $-0.040^{* * *}$ & $0.035^{* *}$ & -0.105 & $-138.336^{* * *}$ & 20.129 & & & & 0.039 \\
\hline
\end{tabular}

The signs $*, * *$ and $* * *$ denote significance at the $10 \%, 5 \%$, and $1 \%$ levels, respectively.

Table 7 shows the cross-sectional results at the individual stock level under the condition that all liquidity-related values are estimated based on principal components. When the market capitalization and book-to-market ratio are incorporated in the model, the intercept is not statistically different from zero, proving the efficiency of the combined LCAPM. However, we find no evidence to support the size effect in the Japanese stock market, as all coefficients on market capitalization are insignificant. The value effect is strongly supported given the significant coefficients in all regressions. Moreover, the coefficients on $\mathrm{E}\left(C_{i, t}\right)$ and on beta 1 are all significant at the $1 \%$ level in both the combined LCAPM and the single LCAPM. This result shows that the illiquidity and the liquidity-adjusted market risk are indispensable when considering the asset pricing model.

In addition to the traditional trading cost, the liquidity risk caused by the comovement of an individual security and the whole market is worth studying. Specifically, the coefficients on beta 3 are significant at the 1\% level in all regressions, and those on beta 4 are significant at the $1 \%$ level in the combined LCAPM. This result demonstrates that the liquidity risk is priced beyond the level of illiquidity and the traditional market risk. We find that beta 2 and beta 5 are significant in most regressions based on 
a single illiquidity proxy but are insignificant in regressions based on principal components likely because the principal components have high correlations with RO and LOT, and beta 2 and beta 5 are not significant in the regressions based on RO and LOT, respectively. Thus, in regressions using the principal component as an illiquidity proxy, beta 2 and beta 5 are insignificant.

Furthermore, we find that the combined LCAPM that considers all four liquidity risks has the highest explanatory power (10.1\%) for stock returns, and this result is $1 \%$ higher than the highest adjusted Rsquared value for the regressions based on single illiquidity measures. As explained by Kim and Lee (2014), the model improves slightly when using principal components rather than a single illiquidity measure.

In summary, our finding suggests that when studying the pricing of liquidity risk, using principal components is superior to using a single illiquidity measure in terms of the R-squared values for cross-sectional returns and p-values in specification tests. Another benefit of using principal components is that allows for unified liquidity risk conclusions. When using a PCA-based illiquidity proxy, the liquidity risk caused by the comovement of a security's price and the market liquidity and that caused by the covariance between a security's illiquidity and the market return are worthy of focus. However, when using a single illiquidity measure, we suggest choosing the turnover ratio, ILLIQ, or LOT, which focus on the trading quantity, the price impact, and the trading cost, respectively, to estimate Japanese stock liquidity in view of the significant coefficients and explanatory powers of the regressions and their high correlations with principal components.

\section{CONCLUSION}

In this study, we analyze the fitness of the LCAPM using different illiquidity proxies and different test assets. Following Kim and Lee (2014), we first run cross-sectional regressions at the stock level. The adjusted R-squared values range from $3.0 \%$ to $4.8 \%$ in regressions using the single LCAPM and from $7.5 \%$ to $9.1 \%$ in regressions using not only liquidity risk factors but also the market capitalization and the book-to-market ratio. We suggest that the size and value effect should be considered together when studying the pricing of liquidity risk because doing so increases the significance levels of transaction costs and liquidity risks. At the individual stock level, the expected liquidity cost, the book-to-market ratio, the commonality liquidity risk (beta 2), the liquidity risk caused by the covariation between an asset's return and the market liquidity (beta 3), and the liquidity risk caused by the covariation between the security's illiquidity and the market return (beta 4) are significantly priced, although the explanatory powers and liquidity risks are sensitive to the illiquidity measures. Specifically, Amihud's ILLIQ, the turnover ratio, and Lesmond, Ogden, and Trzcinka's LOT perform the best among six illiquidity measures.

We then run regressions using size portfolios, size-B/M portfolios, and illiquidity portfolios as test assets. The pricing of liquidity risk varies across the illiquidity measures and test portfolios in most cases. However, the conclusion that the liquidity risk estimated using gamma has the lowest explanatory power is generally tenable. Consistent with previous studies, we also verify that the liquidity risk is not priced in liquidity portfolios.

Given the sensitivity of the results based on test portfolios, we mainly focus on the results using individual stocks as test assets, and we repeat the cross-sectional regressions using a PCA-based measure of illiquidity. The results demonstrate the efficiency of the LCAPM, as the intercept is not statistically different from zero when the market capitalization and the book-to-market ratio are incorporated in the model. Moreover, we find that the traditional illiquidity and the liquidity-adjusted market risk are indispensable when considering the asset pricing model. In addition to the trading cost, the liquidity risk caused by the comovement of a security's price and the market liquidity (beta 3) and that caused by the covariance between the security's illiquidity and the market return (beta 4) are priced as well. This result demonstrates that the liquidity risk is priced beyond the level of illiquidity and the traditional market risk.

Furthermore, we find that the combined LCAPM that considers all four liquidity risks has the highest explanatory power $(10.1 \%)$ for stock returns, and this result is about $1 \%$ higher than the highest adjusted 
R-squared value for the regressions based on single illiquidity measure. Thus, our study suggests that when analyzing the pricing of liquidity risk, using principal components is superior to using a single illiquidity measure in terms of the R-squared value for cross-sectional returns and p-values in specification tests. However, when using a single illiquidity measure, we suggest using the turnover ratio, ILLIQ, or LOT, which focusing on the trading quantity, the price impact, and the trading cost, respectively, to estimate Japanese stock liquidity, in view of the significant coefficients and explanatory powers of the regressions and their high correlations with principal components.

This study has a few important limitations. First, we do not consider variations in the asset holding period. By using monthly variables, we implicitly assume that the holding period for a sample asset is one year. In addition, we do not take into account the influence of the bursting of the Japanese asset price bubble in 1990 or that of the launching of the arrowhead trading system in the Tokyo Stock Exchange in 2010. When suggesting the illiquidity proxies for the principal component analysis, we just consider the correlations between liquidity measures and principal components. However, the principal components' coverage of the illiquidity measures and the tendencies of the liquidity dimensions should be further investigated to help discover a representative illiquidity measure and to strengthen the conclusions regarding liquidity pricing. Finally, we do not compare the performance of the LCAPM to those of other popular asset pricing models, such as Carhart's (1997) four factor model and Fama and French's (2015) five factor model. We think that comparing these asset pricing models could aid in understanding the correlations among the risk factors and finding the most suitable pricing model for the Japanese stock market. Thus, investigating liquidity risk in different holding periods and different sample periods, analyzing the representative PCA-based illiquidity proxies, and considering liquidity risk's interrelationships with other factors may be worthwhile directions for future studies.

\section{ENDNOTE}

1. We do not use the effective tick (ET) measure of Goyenko et al. (2009) or the bid-ask spread estimator (CS) of Corwin and Schultz (2012), which are used by Kim and Lee (2014). We cannot compute ET because tick size depends on the stock price level in Japan. We avoid the CS measure because we do not have open-high-low-close price data from 1977 to 1995. In Japan, the tick-by-tick quote and transaction data are only available from 1996. 


\section{REFERENCES}

Acharya, V., \& Pederson, L.H. (2005). Asset pricing with liquidity risk. Journal of Financial Economics, $77(2), 475-410$.

Amihud, Y. (2002). Illiquidity and stock returns: cross-section and time-series effects. Journal of Financial Markets, 5(1), 31-56.

Berk, J.B. (2000). Sorting out sorts. Journal of Finance, 55(1), 401-427.

Brennan, M.J., Chordia, T., \& Subrahmanyam, A. (1998). Alternative factor specifications, security characteristics and the cross-section of expected stock returns. Journal of Financial Economics, 49(3), 345-373.

Chordia, T., Roll, R., \& Subrahmanyam, A. (2000). Commonality in liquidity. Journal of Financial Economics, 56(1), 3-27.

Conroy, R., Harris, R., \& Benet, B. (1990). The effects of stock splits on bid-ask spreads. Journal of Finance, 45(4), 1285-1295.

Datar, V.T., Naik, N.Y., \& Radcliffe, R. (1998). Liquidity and stock returns: An alternative test. Journal of Financial Markets, 1(2), 203-209.

Fama, E.F., \& French, K.R. (2004). The Capital Asset Pricing Model: Theory and Evidence. Journal of Economic Perspectives, 18(3), 25-46.

Goyenko, R.Y., Holden, C.W., \& Trzcinka, C.A. (2009). Do liquidity measures measure liquidity? Journal of Financial Economics, 92(2), 153-181.

Hasbrouck, J., \& Seppi, D.J. (2001). Common factor in prices, order flows, and liquidity. Journal of Financial Economics, 59(3), 383-411.

Huberman, G., \& Halda, D. (2001). Systematic liquidity. Journal of Financial Research, 24(2), 161-178.

Kim, S.H., \& Lee, K.H. (2014). Pricing of liquidity risks: Evidence from multiple liquidity measures. Journal of Empirical Finance, 25, 112-133.

Korajczyk, R.A., \& Sadka, R. (2008). Pricing the commonality across alternative measures of liquidity. Journal of Financial Economics, 87(1), 45-72.

Lesmond, D.A., Ogden, J.P., \& Trzcinka, C.A. (1999). A new estimate of transaction costs. Review of Financial Studies, 12(5), 1113-1141.

Liu, W. (2006). A liquidity-augmented capital asset pricing model. Journal of Financial Economics, 82(3), 631-671.

Pastor, L., \& Stambaugh, R.F. (2003). Liquidity risk and expected stock returns. Journal of Political Economy, 111(3), 642-685.

Roll, R. (1984). A simple implicit measure of the effective bid-ask spread in an efficient market. Journal of Finance, 39(4), 1127-1139.

Sadka, R. (2006). Momentum and post-earnings-announcement drift anomalies: the role of liquidity risk. Journal of Financial Economics, 80(2), 309-349. 